\title{
Factors influencing clinic attendance during the multidrug therapy of leprosy
}

\author{
P LANGHORNE, P DUFFUS, J S BERKELEY \\ \& K JESUDASAN* \\ Foresterhill House, Ashgrove Road West, Aberdeen AB98AQ; \\ * Schieffelin Leprosy Research and Training Centre, Karigiri, via \\ Katpadi, North District, Tamil Nadu, 632106 South India
}

\begin{abstract}
Accepted for publication 16 August 1986
Summary Factors influencing clinic attendance during multidrug therapy (MDT) of leprosy were studied in a population of paucibacillary patients at Schieffelin Leprosy Research and Training Centre (SLR \& TC) Karigiri in Southern India. Information was gathered from patient records ( 293 patients) and by questionnaires (143 patients). Patients were grouped according to their long-term clinic attendance record. Factors associated with poor clinic attendance were detection by survey, poor attendance during dapsone monotherapy and longer periods of treatment with dapsone monotherapy prior to MDT, and absence from first or second clinics after registration for MDT. Factors associated with good clinic attendance were presence of deformity and voluntary presentation. Factors unrelated to clinic attendance were age, sex, clinic size, site or number of skin lesions and type of paucibacillary leprosy. The commonest reason given for clinic absences were work and family commitments. Various schemes for predicting poor clinic attendance behaviour were devised.
\end{abstract}

\section{Introduction}

Patient compliance with recommended treatment regimes is an important aspect of leprosy management. The successful mass treatment of leprosy is largely dependent on the regularity with which outpatients receive their drug therapy. ${ }^{9}$ Furthermore, irregularity of dapsone (DDS) treatment was probably a major factor in the emergence of DDS-resistant strains of Mycobacterium leprae. ${ }^{5,6,11}$

Factors affecting the attendance regularity of leprosy patients have been studied during DDS monotherapy in Ethiopia, ${ }^{3}$ Tanzania ${ }^{4}$ and India. ${ }^{1,2,8,10,12}$ Studies of patient records have identified several factors, e.g. degree of deformity, distance from clinic, season; which appear to influence attendance regularity, while questionnaire studies have indicated a wide range of reasons for poor attendance, e.g. ignorance, social stigma, distance from clinic. 
Since 1982, many leprosy treatment programmes have introduced multidrug therapy (MDT) in an attempt to reduce treatment times and counter the problems of DDS resistance. ${ }^{14}$ There is concern ${ }^{9}$ that poor patient compliance will seriously restrict the effectiveness of MDT.

The present investigation consisted of two parts; 1 , a retrospective survey of factors related to poor clinic attendance and; 2 , a questionnaire study to ascertain if patients exhibiting poor compliance behaviour have more difficulties to overcome than good attenders. Paucibacillary (PB) patients were studied since they form the great majority of leprosy patients ${ }^{7}$ and are subject to less rigorous 'patient retrieval' procedures than multibacillary (MB) patients. ${ }^{14}$

\section{Materials and methods}

The Schieffelin Leprosy Research and Training Centre is responsible for leprosy control in the Gudiyatham Taluk, North Arcot District, South India. This rural Taluk has a population of 426,000 , a leprosy prevalence rate of $13 / 1000$ and an incidence rate of about $1 / 1000$. The SLR and TC has been running a leprosy control programme since 1962, and began implementing MDT in 1982.

The Gudiyatham Taluk is divided into four blocks for the purposes of leprosy control programmes. Within each block are several village clinics (arranged to reduce patient travel to less than 3 miles) which are operated on a monthly basis. A register recording all patients who have commenced on MDT course for leprosy was used to identify all paucibacillary (PB) patients on MDT between 1982 and September 1985. Data were then taken from the identified patient's records.

\section{Record survey}

Block 1 of the Gudiyatham was chosen because it contained an accessible, representative sample ( $27 \%$ of PB cases on MDT) of the whole Taluk. The PB patient register recorded 403 patients who had commenced MDT. Eighty-nine were excluded from the record survey study since they had not yet had the opportunity to attend 6 monthly clinics, i.e. treatment commenced after March 1985. A further 18 patients had left the area, or died, before completion of MDT. The records of 3 patients were not traced. This produced a study population of 293 PB patients which formed the basis of the record survey study. The investigation into early prediction of attendance behaviour included some data obtained from clinics outside Block 1 (see Results).

\section{Questionnaire study}

The study population consisted of patients within Block 1, and without any deformity, ${ }^{13}$ who had commenced MDT more than 5 months before the 
interview, and who were either still under treatment or follow-up, i.e. within a few months of the completion of MDT.

Patients were interviewed at the monthly clinics and clinic absentees visited at home. One domiciliary visit only was possible within each clinic area and priority was given to patients currently under treatment. Patients who could not be contacted during that visit had to be excluded from the study.

The questionnaire was designed to detect difficulties experienced by patients in attending clinics (regardless of actual attendance rates), and to assess their attitude towards the diagnosis and treatment. Most questions required a 'Yes' or 'No' answer. Patients were interviewed with the help of a translator using a standard Tamil version of the questionnaire. The interviews lasted less than 5 minutes each. The same translator was úsed at all clinic interviews, but several were involved in the domiciliary visits. Wherever possible, children were interviewed with their parent or guardian.

\section{Data analysis}

The majority of analyses used the non-parametric $\chi$-square test, with the Yates' correction for small numbers where appropriate. The correlation of attendance rates on DDS and MDT was carried out using a microcomputer.

\section{Results}

The study population was divided into two non-defaulter groups on the basis of recommended attendance rates for paucibacillary (PB) patients. ${ }^{14}$

Non-defaulters: a, excellent attenders (EA), 100\% attendance over 6 months; b, acceptable attenders (AA), 67-99\%; i.e. compatible with the completion of 6 month MDT course within 9 months.

Defaulters: a, unacceptable attenders (UA), less than $67 \%$ attendance, i.e. incompatible with the successful completion of the drug regime.

The numbers of patients in each attendance group were as follows: EA, 129 patients ( $44 \%$ of the study population); AA, 107 patients (37\%); UA, 57 patients $(19 \%)$.

Thus the total default rate was $19 \%$ of patients.

\section{Factors related to clinic attendance}

These were investigated by observing variations between the three attendance groups (EA, AA, UA). 
1 Age and sex. Attendance behaviour was unrelated $(P>0 \cdot 5)$ to the age or sex of the patient (Table 1).

2 Occupation. A large number of patient records were inadequate in this aspect. Among the completed records, there was no significant relationship $(P>0.5)$ between the six occupation groups. (Housewife, professional/student, clerk/ office worker, craftsman, farmer/coolie/labourer, beggar/unemployed) and clinic attendance.

3 Clinic size. When considered within three groups (less than 100 patients, 100 150 patients, 151-200 patients), clinic size was unrelated to attendance rates $(0 \cdot 5>P>0 \cdot 1)$.

4 Disease classification. There was no statistically significant relationship $(P>0.5)$ between disease classification and attendance groups (Table 2$)$.

5 Skin lesions. The site of skin lesions (i.e. face, right arm, left arm, right leg, left leg, trunk) was unrelated to clinic attendance $(P>0 \cdot 5)$. This conclusion was not altered when the presence or absence of anaesthesia in skin lesions was taken into account. The number of sites containing skin lesions was unrelated to attendance $(0.5>\mathrm{P}>0 \cdot 1)$ once the patients with deformities were removed from the analysis (see below).

6 Nerve lesions. The site of nerve involvement (facial, great auricular, ulnar, median, radial, lateral popliteal, posterior tibial), and the number of nerves enlarged, had no significant relationship with clinic attendance groups $(P>0.5$ and $0 \cdot 5>P>0 \cdot 1$ respectively).

7 Deformity. This was recorded using the WHO scale. ${ }^{13}$ Data were insufficient to study the influence of deformity grade or the site of deformity, on clinic

Table 1. Age and sex distribution (\%).

\begin{tabular}{|c|c|c|c|c|c|c|}
\hline \multirow{2}{*}{$\begin{array}{l}\text { Age } \\
\text { (years) }\end{array}$} & \multicolumn{2}{|c|}{ EA } & \multicolumn{2}{|c|}{$\mathrm{AA}$} & \multicolumn{2}{|c|}{ UA } \\
\hline & $\mathbf{M}$ & $\mathrm{F}$ & M & $\mathrm{F}$ & $\mathbf{M}$ & $\mathrm{F}$ \\
\hline$<15$ & 24 & 28 & 20 & 28 & 27 & 29 \\
\hline $15-34$ & 40 & 39 & 53 & 42 & 51 & 37 \\
\hline $35-54$ & 28 & 24 & 19 & 32 & 16 & 21 \\
\hline$>54$ & 8 & 9 & 8 & 8 & 6 & 13 \\
\hline Total (\%) & 100 & 100 & 100 & 100 & 100 & 100 \\
\hline Total No. & 75 & 54 & 54 & 53 & 33 & 34 \\
\hline$\chi$-square & \multicolumn{2}{|c|}{$P>0.5 \mathrm{NS}^{*}$} & & & & \\
\hline
\end{tabular}

* NS denotes a non-significant result.

EA, excellent attenders; AA, acceptable attenders; UA, unacceptable attenders. 
Table 2. Disease classification (\%).

\begin{tabular}{lrrr}
\hline Classification & EA & AA & UA \\
\hline TT & 42 & 47 & 51 \\
BT & 47 & 45 & 40 \\
I & 11 & 8 & 9 \\
Total (\%) & 100 & 100 & 100 \\
Total No. & 129 & 107 & 57 \\
$\chi$-square & $P>0.5$ NS \\
\hline
\end{tabular}

Leprosy classification: TT, tuberculoid; BT, borderline tuberculoid; I, indeterminate.

Table 3. Presence of deformity $(\%)$.

\begin{tabular}{lrrr}
\hline Deformity & EA & AA & UA \\
\hline Yes & 17 & 7 & 4 \\
No & 83 & 93 & 96 \\
Total (\%) & 100 & 100 & 100 \\
Total No. & 129 & 107 & 57 \\
$\chi$-square & $P<0.01$ & \\
\hline
\end{tabular}

attendance. When the presence or absence of any deformity was considered (Table 3$)$, the presence of deformity was significantly related $(P<0.01)$ to good attendance.

8 Foot injury. In the whole study population there were only 5 cases of severe foot injury. They were all in the EA and AA groups.

9 Mode of detection. This was found to have a significant relationship $(P<0.01)$ with clinic attendance (Table 4$)$. The three different categories within the survey group (general survey, contact survey, school survey) did not differ $(P>0.5)$ with respect to clinic attendance.

10 Presence of leprosy contacts. There was no relationship $(P>0 \cdot 5)$ with clinic attendance.

11 Duration of disease prior to registration. This was unrelated to clinic attendance $(0 \cdot 5>P>0 \cdot 1$; Table 5$)$.

12 Length of treatment. Longer treatment times prior to MDT (i.e. on DDS) 
Table 4. Mode of detection (\%).

\begin{tabular}{lrrr} 
Detection & EA & AA & UA \\
Survey & 52 & 61 & 78 \\
Voluntary & 48 & 39 & 22 \\
Total (\%) & 100 & 100 & 100 \\
Total No. & 123 & 99 & 55 \\
$\chi$-square & $P<0.01$ & \\
\hline
\end{tabular}

Table 5. Duration of disease prior to registration $(\%)$.

\begin{tabular}{lrrr} 
Duration & EA & AA & UA \\
\hline <3 months & 24 & 16 & 24 \\
3 months-1 year & 47 & 40 & 43 \\
1 year-3 years & 17 & 25 & 13 \\
> 3 years & 12 & 19 & 20 \\
Total (\%) & 100 & 100 & 100 \\
Total No. & 112 & 85 & 46 \\
$\chi$-square & $0.5>P>0.1 \mathrm{NS}$ \\
\hline
\end{tabular}

Table 6. Length of treatment prior to MDT (\%).

\begin{tabular}{lrrr} 
Treatment time & EA & AA & UA \\
\hline 0-10 months & 58 & 45 & 39 \\
$11-20$ months & 24 & 16 & 14 \\
$21-40$ months & 9 & 18 & 23 \\
$>40$ months & 9 & 21 & 24 \\
Total (\%) & 100 & 100 & 100 \\
Total No. & 129 & 107 & 57 \\
$\chi$-square & $P<0.001$ \\
\hline
\end{tabular}


Table 7. Attendance rates during previous DDS monotherapy.

\begin{tabular}{lcc}
\hline & & \multicolumn{1}{c}{ Attendance on DDS } \\
MDT group & $n$ & $\%$ of possible attendance) \\
\hline EA & 72 & $94 \cdot 3 \pm 1 \cdot 1$ \\
AA & 64 & $86 \cdot 5 \pm 1 \cdot 8$ \\
UA & 42 & $74.9 \pm 2 \cdot 8$ \\
\hline
\end{tabular}

Data are presented as the Mean \pm SEM of 'n' cases.

All groups differ from each other $(P<0.01)$ by the Student's $t$-test.

were associated with poorer attendance (Table $6, P<0.001$ ). The possible effect of attendance behaviour on treatment time, which when poor might be expected to lengthen the time on DDS monotherapy, is not known (see Discussion).

13 Previous compliance behaviour. The clinic attendance rates of patients on DDS monotherapy were compared with their subsequent attendance on MDT. This analysis used only cases with at least 6 months of DDS therapy prior to MDT. Attendance rates on DDS monotherapy reflected attendance during MDT (Table 7) indicating that poor compliance was evident before MDT. Linear regression analysis of individual DDS and MDT attendance rates revealed a significant correlation $(r=0.48, P<0.001 ; n=178$ patients) between the two.

14 Clinic of first absence. The first clinic to be missed (after one initial attendance) was recorded and a comparison made between AA and UA groups

Table 8. Clinic of first absence $(\%)$.

\begin{tabular}{crr}
\hline Clinic number & AA & UA \\
\hline 2 & 21 & 68 \\
3 & 26 & 16 \\
4 & 28 & 11 \\
5 & 15 & 5 \\
6 & 10 & 0 \\
Total (\%) & 100 & 100 \\
Total No. & 107 & 57 \\
$\chi$-square & $P<0.001$ \\
\hline
\end{tabular}


(Table 8$)$. The two groups differed markedly $(P<0.001)$. This appears to be due to the much higher probability of the UA patients missing any one clinic. Thus unacceptable attendance behaviour is usually evident early during MDT.

15 Seasonal variation in clinic attendance. The seasonality of clinic attendance was investigated for both MDT and DDS (where the patient had previously been on DDS monotherapy). All attendance results were expressed as a percentage of the number of patients under treatment during 1 calendar month and data accumulated over several years.

When all data were included (i.e. EA, AA, and UA groups) a marked seasonality was evident. When on MDT, attendances were lowest in June and July, and highest in October and November (numbers of patients under treatment each month ranged from 95 to 203). The pattern was similar on DDS monotherapy; attendance was low in January, May and June and high in August and October (572 patients were under treatment each month). Both MDT and DDS seasonal patterns were significant $(P<0.001$ and $P<0.05$ respectively) by the $\chi$-square test.

A comparison of defaulters (UA) and non-defaulters (EA and AA) on MDT revealed similar patterns (Figure 1). Peak attendance among non-defaulters was in October, compared with November for defaulters. Poorest attendance was in May for non-defaulters and June-July for defaulters. Monthly totals of patients under treatment ranged between 78 and 155 in the non-defaulter group, and from 17 to 57 in the defaulter group. In both groups the seasonal pattern was significant $(P<0.001$ and $P<0.01$ respectively).

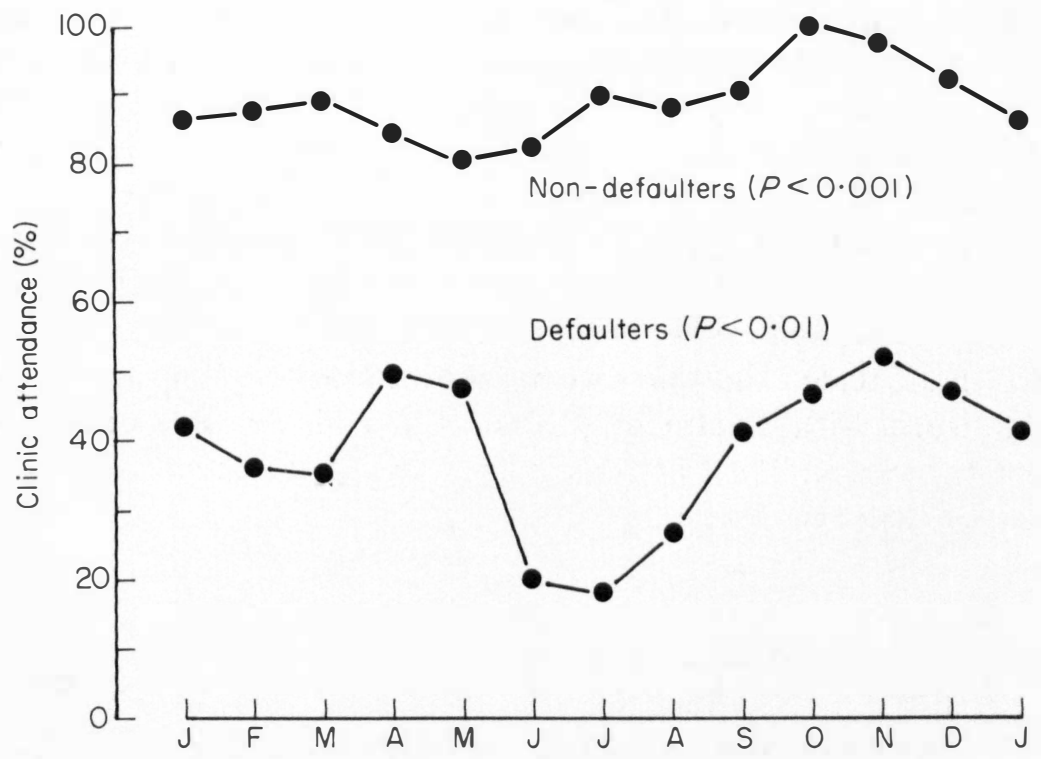

Figure 1. Seasonal variation in clinic attendance during multidrug therapy. 
Table 9. Reasons for having difficulty attending clinics. Numbers and $\%$ of patients in each "clinic attendance behaviour' group with each 'difficulty'.

\begin{tabular}{|c|c|c|c|c|c|c|c|c|}
\hline & \multicolumn{2}{|c|}{$\begin{array}{c}\text { EA } \\
\text { (Total 47) }\end{array}$} & \multicolumn{2}{|c|}{$\begin{array}{c}\text { AA } \\
\text { (Total 48) }\end{array}$} & \multicolumn{2}{|c|}{$\begin{array}{c}\text { UA } \\
\text { (Total 48) }\end{array}$} & \multicolumn{2}{|c|}{$\begin{array}{c}\text { Overall } \\
\text { (Total 143) }\end{array}$} \\
\hline & No. & $\begin{array}{c}(\% \text { of } \\
\text { total } \\
\text { EA })\end{array}$ & No. & $\begin{array}{c}(\% \text { of } \\
\text { total } \\
\text { AA) }\end{array}$ & No. & $\begin{array}{c}(\% \text { of } \\
\text { total } \\
\text { UA) }\end{array}$ & No. & $\begin{array}{c}\text { (\% of } \\
\text { overall } \\
\text { total) }\end{array}$ \\
\hline Work commitments & 1 & (2) & 10 & $(21)$ & 19 & $(40)$ & 30 & $(21)$ \\
\hline Family commitments & 1 & (2) & 14 & (29) & 22 & (46) & 37 & (26) \\
\hline Religious commitments & 0 & (0) & 2 & (4) & 0 & (0) & 2 & (1) \\
\hline Distance to clinics & 4 & (9) & 2 & (4) & 4 & (8) & 10 & (7) \\
\hline Stigma & 2 & (4) & 3 & (6) & 4 & $(8)$ & 9 & (6) \\
\hline Other & 0 & (0) & 9 & (19) & 12 & $(25)$ & 21 & (15) \\
\hline
\end{tabular}

\section{Questionnaire studies}

The three attendance groups (EA, AA and UA) were used in this investigation.

The commonest reasons for having difficulty attending clinics were those of family $(26 \%)$ and work $(21 \%)$ commitments, both of which increased in frequency as attendance rate declined (Table 9). These commitments interfered with the monthly clinics, or with the paramedical worker's visits to remind patients about the clinics. The 'other reasons' group was also an important reason $(15 \%)$ for attendance difficulties. Religious commitments, stigma and travel distance presented difficulties in $14 \%$ of the patients but were present equally in all attendance groups (Table 9). Patients frequently claimed to have no difficulty in attending clinics despite poor attendance rates and would admit to problems only on direct challenge.

Most patients when asked if they accepted the diagnosis of leprosy responded by pointing to the skin lesion(s), and $43 \%$ accepted that this was due to leprosy. Acceptance of the diagnosis was unrelated to clinic attendance rate (Table 10). Only $4 \%$ of patients felt that their treatment was unnecessary, and $6 \%$ admitted being unsatisfied with treatment (Table 10). This did not appear to affect attendance behaviour. The patient's knowledge of treatment duration did not affect clinic attendance (Table 11).

\section{Early prediction of attendance behaviour}

The results obtained in the records survey indicated several possible indices of attendance behaviour. These indices (i.e. presence of deformity, mode of 
Table 10. Attitudes towards treatment and diagnosis.

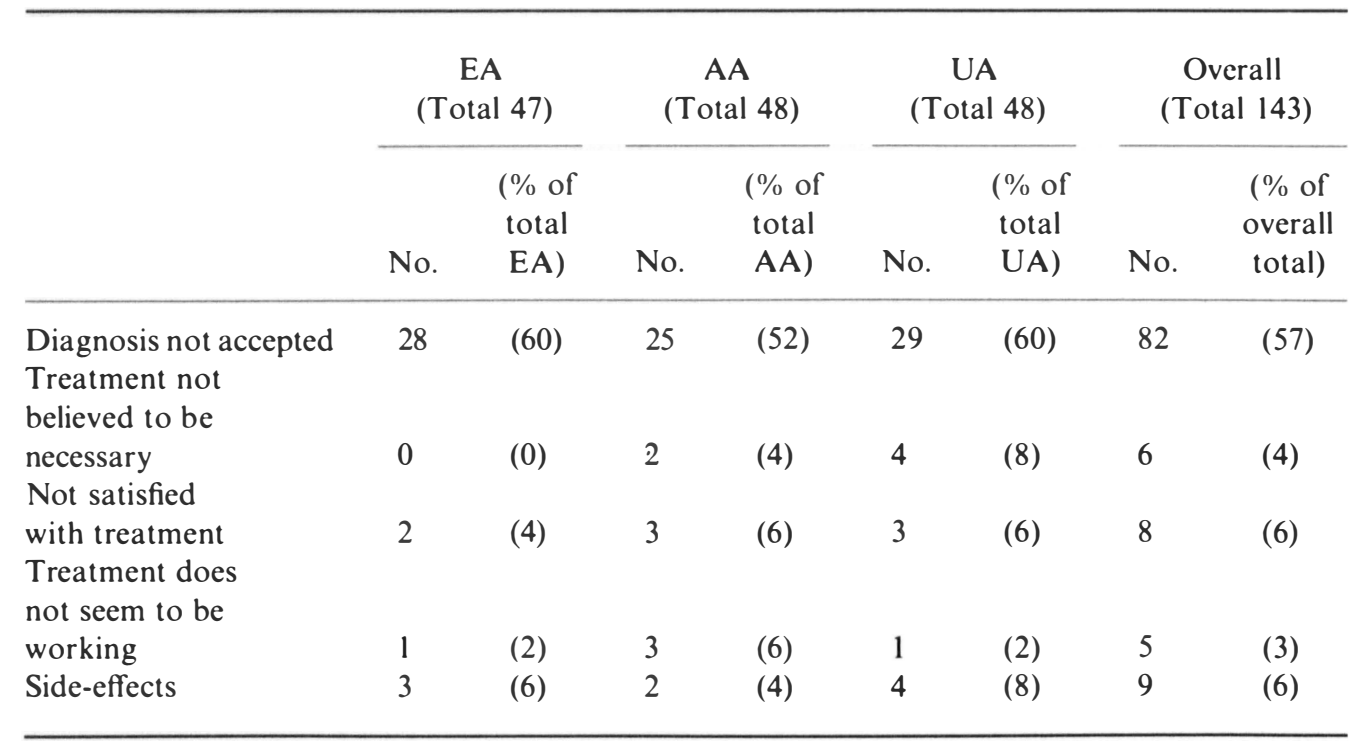

Table 11. Knowledge of treatment duration. (Answers in reply to the question 'How long do you have to take treatment to be cured of leprosy?')

\begin{tabular}{|c|c|c|c|c|c|c|c|c|}
\hline & \multicolumn{2}{|c|}{$\begin{array}{c}\text { EA } \\
\text { (Total 47) }\end{array}$} & \multicolumn{2}{|c|}{$\begin{array}{c}\text { AA } \\
\text { (Total 48) }\end{array}$} & \multicolumn{2}{|c|}{$\begin{array}{c}\text { UA } \\
\text { (Total 48) }\end{array}$} & \multicolumn{2}{|c|}{$\begin{array}{c}\text { Overall } \\
\text { (Total 143) }\end{array}$} \\
\hline & No. & $\begin{array}{c}(\% \text { of } \\
\text { total } \\
\text { EA })\end{array}$ & No. & $\begin{array}{c}(\% \text { of } \\
\text { total } \\
\text { AA) }\end{array}$ & No. & $\begin{array}{l}\text { (\% of } \\
\text { total } \\
\text { UA) }\end{array}$ & No. & $\begin{array}{c}(\% \text { of } \\
\text { overall } \\
\text { total })\end{array}$ \\
\hline Don't know & 17 & (36) & 20 & $(42)$ & 23 & (48) & 60 & $(42)$ \\
\hline Six months & 15 & (32) & 18 & (37) & 13 & (27) & 46 & (32) \\
\hline More than & & & & & & & & \\
\hline 6 months & 15 & $(32)$ & 10 & $(21)$ & 12 & $(25)$ & 37 & (26) \\
\hline
\end{tabular}

detection and timing of absences) were investigated using patient data obtained from clinics within, and outside of block 1, Gudiyatham Taluk. As the results were very similar between clinics, data were combined into a patient population of 360 , of which $68(18.9 \%)$ were unacceptable attenders.

The observed 'sensitivity' and 'specificity' (for definitions see Table 12) of three simple 'predictive schemes' in predicting poor clinic attendance are displayed in Table 12. 
Table 12. The use of 'predictive schemes' in the early prediction of poor clinic attendance.

\begin{tabular}{llcc}
\hline Scheme & \multicolumn{1}{c}{$\begin{array}{c}\text { Sensitivity } \\
\text { No. }\end{array}$} & $\begin{array}{c}\text { Specificity } \\
\text { Features of the } \\
\text { predictive schemes } \\
\text { (Proportion of the } \\
\text { correctly identified) }\end{array}$ & $\begin{array}{c}\text { (Pon-defaulter population } \\
\text { correctly identified) }\end{array}$ \\
\hline 1 & $\begin{array}{l}\text { Absent from both } \\
\text { 2nd and 3rd clinics } \\
\text { Absent from 2nd } \\
\text { and/or 3rd clinics } \\
\text { Absent from 2nd } \\
\text { clinic and/or 3rd } \\
\text { clinic and/or } \\
\text { survey detection }\end{array}$ & $56 \%$ & $98 \%$ \\
\hline
\end{tabular}

\section{Discussion}

The design of the present study, and the facilities available to carry it out, differ considerably from those of earlier investigations. Earlier workers ${ }^{1,3,4,8,10}$ have studied whole leprosy patient populations during dapsone (DDS) monotherapy, in contrast to the present population of paucibacillary (PB) patients on MDT. The low overall default rate reported here could be due to the short-treatment time, improved case-holding, or more frequent supervision present in MDT. ${ }^{14}$ However it is to be noted that the unacceptable attender rate in the paucibacillary group is $19 \%$ despite the high level of supervision in Gudiyatham Taluk. In addition, improvements in domiciliary programmes suggested by earlier studies have influenced the planning of current programmes, e.g. travelling distances. Thus, some of the discrepancies between this study and its predecessors reflect differences in the organization of DDS monotherapy in the past, and MDT at present.

The survey of patient records identified several features among attendance defaulters (lack of deformities, detection by survey, lengthy treatment before MDT, previous bad compliance, early first absence, marked seasonality), which are in agreement with previous studies, ${ }^{3,4,8}$ although Giel and van Luijk ${ }^{3}$ found no relationship with deformity. Seasonal variations, which were evident among both acceptable attenders (AA) and unacceptable attenders (UA) are discussed below.

The most important negative findings of the present study involved the failure to relate patient age, sex, occupation, clinic size, disease classification or duration of disease with clinic attendance. Hertroijs ${ }^{4}$ reported that in Tanzania attendance varied with age and sex, but this has not been confirmed by Indian studies. ${ }^{1,10}$ Patient occupation, which Nigam ${ }^{10}$ indicated may influence clinic attendance, 
was difficult to examine in the present study because of incomplete records. The clinics in this investigation were larger and more uniform in size than those of Hertroijs, ${ }^{4}$ thus a significant influence of clinic size was less likely to be found. Earlier studies incorporating disease classification ${ }^{4,8}$ have encompassed all leprosy types, in contrast to the PB population reported here. This has reduced the range of disease types and may account for the discrepancy. The difference between the present study and that of Hertroijs, ${ }^{4}$ regarding disease duration eludes simple explanation. The great cultural differences between Tanzania and India cannot be excluded.

Seasonality in attendance rate was evident regardless of the attendance groups or drug regimens, i.e. poor attendance May-July, good attendance October-November. Previous studies ${ }^{1,4}$ have implicated seasonal migrations, climatic features (especially monsoons) and agricultural activity. None of these reasons easily account for the present findings. Seasonal migrations are not a major feature of South Indian life although some movement occurs to find work. The very hot weather of May-June may be reducing attendance, but the monsoons (September-January) appear to have no influence. The period of peak agricultural activity, the groundnut harvests of September and JanuaryFebruary are associated with good attendance. One speculative explanation is that the groundnut harvest keeps patients within the local area, i.e. close to the clinic. When agricultural activity is low, many people may have to travel to find temporary work outside the clinic area. An additional consideration is the influence of family/social commitments, since May-June is a common time for weddings in Tamil Nadu. The questionnaire studies are interesting in this context.

The two main reported reasons for difficulty in attending clinics were family and work commitments. Poor clinic attenders admitted to more of these problems than good attenders. However, within the UA group, reasons given for absenteeism were not always adequate to explain all the absences, e.g. weddings or funerals given as the sole reason. It is likely that other important factors such as personality and motivation were responsible. John et al. ${ }^{6}$ demonstrated that personality is important during self-administration of dapsone, and the same may also be true of attendance compliance. Improved 'motivation' may be provided by intensive patient retrieval procedures, such as are applied to multibacillary (MB) patients on $\mathrm{MDT},{ }^{14}$ and this may explain the generally good clinic attendance in this group.

Travelling distance was not a problem, presumably because clinics have been arranged to minimize this problem. It would appear that acceptance of the seriousness of the disease and of the importance of regular treatment, are more significant determinants of good compliance behaviour than a specific knowledge of leprosy or its treatment. The low number of respondents stating that treatment was unnecessary or unsatisfactory indicates that patient education has been effective in this aspect.

The picture of a poor clinic attender which arises from this study is that of a 
patient with little awareness or motivation regarding his disease (hence survey detection), and no serious complications to change his attitudes. The attendance, which is poor on DDS, evidently worsens with the length of treatment. Patient motivation appears to be a key feature and the continued use and improvement of health education may alleviate this problem. It is possible that the shorter treatment time of MDT has improved compliance and that this will become apparent in the near future as more patients are treated with MDT alone.

Previous investigations ${ }^{1,4}$ have outlined features which help predict poor attendance but without quantitative assessment. The reasoning behind the present use of quantitative 'predictive schemes' was that the early identification of future defaulters would allow an efficient use of resources in patient retrieval efforts. In general there is a compromise between 'sensitivity' (i.e. proportion of defaulters identified) and 'specificity' (i.e. proportion of nondefaulters excluded from the group predicted to be defaulters). The most specific scheme (number 1) should provide for efficient patient retrieval programmes contacting about half of all defaulters and could be useful where resources are limited. The other two schemes would require a greater input with respect to paramedical workload, but they would predict the majority of defaulters.

\section{Acknowledgments}

Dr Fritschi and Dr Christian kindly permitted this study to be carried out in the Epidemiology Department of the SLR \& TC. Much friendly assistance was provided by the staff of the Epidemiology and Medical Records Departments. Peter Langhorne and Peter Duffus were given financial assistance by LEPRA and Leprosy Mission respectively.

\section{References}

' Bhagoliwal A, Chandra J, Mishra RS. Some observations on default among leprosy patients. Lepr India, 1979; 51, 96-102.

2 Ekambaram V. Absentism for treatment, their causes and suggested remedial measures. Lepr India, 1974; 46: 46-8.

${ }^{3}$ Giel R, Van Luijk JN. Leprosy in Ethiopian Society. Int J Lepr, 1970; 38: 187-98.

${ }^{4}$ Hertroijs AR. A study of some factors affecting the attendance of patients in a leprosy control scheme. Int J Lepr, 1974; 42: 419-27.

5 Jacobson RR. Sulphone-resistant leprosy: Etiology, incidence and treatment in the United States. Int J Lepr, 1973; 41: 684.

6 John JK, Pannikar VK, Verghesi A, Christian M. Social and personality factors in Dapsone resistance. Lepr India, 1983; 55: 100-6.

7 Jopling WH. Handbook of Leprosy (3rd edition). London: William Heinemann Medical Books Ltd, 1984.

${ }^{8}$ Karat ABA, Job CK, Karat S, Sadananda Rao G, Rao PSS. Domiciliary treatment programme absentee survey. Lepr India, 1967; 39: 180-9. 
9 Lancet Editorial. Chemotherapy of Leprosy. Lancet, 1982; ii: 77-8.

${ }^{10}$ Nigam P, Siddique MIA, Pandey NR, Awasthi KN, Sriwastava RN. Irregularity of treatment in leprosy patients: Its magnitude and causes. Lepr India, 1979; 51: 521-32.

1 Rees RJW. Drug resistance of Mycohacterium Leprae, particularly to DDS. Int J Lepr, 1967; 35: 625.

12 Vellut C, Alex L, Ethirajan T. Study of the reasons for absenteeism. Lepr India, 1979; 51: 568.

13 WHO. WHO classification of disabilities resulting from leprosy, for the use in control projects. Lepr Rev, 1970; 41: 53-6.

14 WHO. Chemotherapy of leprosy for control programmes. Geneva: Technical Report Series No. $657,1982$. 